\title{
Risk of non-Hodgkin lymphoma associated with occupational exposure to solvents, metals, organic dusts and PCBs (Australia)
}

\author{
Lin Fritschi ${ }^{1}$, , Geza Benke ${ }^{2}$, Ann M. Hughes ${ }^{3}$, Anne Kricker ${ }^{3}$, Claire M. Vajdic ${ }^{4}$, Andrew Grulich ${ }^{4}$, \\ Jennifer Turner ${ }^{5}$, Samuel Milliken ${ }^{5}$, John Kaldor ${ }^{4} \&$ Bruce K. Armstrong ${ }^{3}$ \\ ${ }^{1}$ School of Population Health, University of Western Australia, Perth, Western Australia; ${ }^{2}$ Department of \\ Epidemiology and Preventive Medicine, Monash University, Melbourne, Australia; ${ }^{3}$ School of Public Health, \\ University of Sydney, Australia; ${ }^{4}$ National Centre in HIV Epidemiology and Clinical Research, University of NSW, \\ Sydney, Australia; ${ }^{5}$ St Vincent's Hospital, Sydney, Australia
}

Received 7 October 2004; accepted in revised form 20 December 2004

Key words: non-Hodgkin lymphoma, occupation, solvents, wood dust.

\begin{abstract}
Objective: Several studies have suggested that there is an occupational component to the causation of non-Hodgkin lymphoma (NHL). We aimed to use accurate means to assess occupational exposures to solvents, metals, organic dusts and polychlorinated biphenyls (PCBs) in a case-control study.

Methods: Cases were incident NHLs during 2000 and 2001 in two regions of Australia. Controls were randomly selected from the electoral roll and frequency matched to cases by age, sex and region. A detailed occupational history was taken from each subject. For jobs with likely exposure to the chemicals of interest, additional questions were asked by telephone interview using modified job specific modules. An expert allocated exposures using the information in the job histories and the interviews. Odds ratios were calculated for each exposure adjusting for age, sex, region and ethnic origin.

Results: 694 cases and 694 controls (70\% and 45\% respectively of those potentially eligible) participated. The risk of NHL was increased by about $30 \%$ for exposure to any solvent with a dose response relationship, subgroup analysis showed the finding was restricted to solvents other than benzene. Exposure to wood dust also increased the risk of NHL slightly. Exposures to other organic dusts, metals, and PCBs were not strongly related to NHL. Conclusions: The risk of NHL appears to be increased by exposure to solvents other than benzene and possibly to wood dust.
\end{abstract}

\section{Background}

In Australia, over the last decade, the incidence of nonHodgkin lymphoma (NHL) has increased by $0.8 \%$ per year in females and by $1.7 \%$ per year in males [1]. The causes of this rise in incidence are not clear. Several occupational risk factors for this cancer have been reported including solvents, pesticides, polychlorinated biphenyls (PCBs), metallic dusts and various organic dusts [2-8].

\footnotetext{
* Author for correspondence: Lin Fritschi, Viertel Centre for Research in Cancer Control, Queensland Cancer Fund, PO Box 201, Spring Hill, Qld, 4004, Australia. E-mail: lfritschi@qldcancer.com.au
}

Many of the previous studies of occupational exposures have used crude methods such as job title or selfassessed exposure to determine exposure status or have used deaths from cancer rather than incident cases. We used more accurate means to assess occupational exposures in a large Australian case-control study of incident NHL. The expert assessment method involves taking a detailed work history of all jobs over the subject's lifetime using a diary [9]. More questions are then asked about various tasks within certain jobs that may involve high exposures to specific chemicals. An expert in occupational exposures reviews the answers to the questions, and allocates exposure to the chemicals. In this paper we report the findings relating to solvents, metal and organic dusts, and PCBs. 


\section{Methods}

Details on the case and control ascertainment for this study can be found in a related publication [10]. Briefly, cases were patients notified to the Central Cancer Registry of New South Wales (NSW) with incident NHL first diagnosed between 1 January 2000 and 31 August 2001. They had to be aged 20-74 years of age and resident in NSW or the Australian Capital Territory (ACT). Ineligibility criteria included a history of transplantation or HIV infection, poor English language skills, and inability to complete telephone interview. Patients with a diagnosis of chronic lymphocytic leukaemia, plasma cell myeloma, and $\mathrm{B}$ and $\mathrm{T}$ lymphoblastic leukaemia were excluded. After obtaining permission from the treating doctor, the Registry wrote to the patient, requesting their consent to their contact details being given to the study investigators. An anatomical pathologist with a particular interest in hematopathology reviewed pathology reports and diagnostic slides for consenting cases to confirm all original diagnoses and to provide, where possible, a cell phenotype and WHO (ICD-03) classification [11].

Controls were randomly selected from the NSW and ACT Electoral Rolls to approximately match the expected distributions of cases with respect to age, sex and region of residence (NSW or ACT). Electoral registration is compulsory for Australian citizens aged 18 years or over. Similar eligibility criteria were used as for cases, except for prior immunosuppression.

Cases and controls were mailed an introductory letter and an information leaflet outlining the requirements of participation, and subsequently telephoned to obtain their verbal consent. A self-administered questionnaire was then mailed to each subject to obtain data on demographic details, smoking status and other variables of interest to the study. In addition, each subject completed a diary with a detailed lifetime occupational history including each job title, employer, industry, start and finish years, number of hours worked per day and number of days worked per week. Participants were requested to only include jobs they had had for one year or more, and, if they had had more than one job in a year, to record the one which they had held for the longest time. A total of 28 jobs and 16 industries were identified as being of particular interest because of the possibility of exposure to the substances of interest in this study. For these 44 jobs and industries, detailed sets of questions (known as job specific modules) were obtained from the National Cancer Institute in the United States [12]. These modules were modified extensively to take into account the specific substances of interest and Australian working conditions. For example, questions which related to diesel exhaust were removed, while some questions specifically relating to PCB exposure were added. In addition, questions referring to winter and summer exposure were omitted as the seasonal variation is much less in Australia than in North America.

The job histories were entered into a spreadsheet and an occupational hygienist, who was blind to case status of the subject, allocated modules to jobs considered likely to have significant exposures. Because of limited interview time, jobs assigned modules were prioritized, with the most highly exposed jobs being asked about early in the interview. We allocated high priority to jobs with a high likelihood of significant levels of exposure, which were done for a long time, or which were likely to have unusual exposures or ones which were difficult to assess without additional information.

A customized computer-assisted telephone interview was carried out with interviewers blinded to the case or control status of subjects. The interviewers were instructed to ask questions until all allocated modules were completed or the time limit for the entire interview was reached, whichever came first. If the interview went overtime, subjects were offered the opportunity to finish the modules at the time, or at a later time more convenient for them.

An expert occupational hygienist reviewed the occupational histories and the answers to the modules and determined exposure to various substances including: benzene (before and after 1985 when changes to the use of benzene in industry occurred); other solvents (aromatics, chlorinated hydrocarbons and aliphatics); toxic metals (nickel, beryllium, cadmium, lead, chromium, mercury, arsenic); other metals; organic dusts (hard woods, soft woods, grain dust, cotton dust, other organic dusts) and PCBs. He first allocated likelihood of exposure to each substance as probable, possible or no exposure. He then allocated level of exposure based on the internationally recognised occupational safety guidelines (time-weighted average threshold limit values (TLV) set by the ACGIH [13]) and without regard to probability of exposure. Levels of exposure higher than the TLV were considered high, those less than or equal to 0.1 of the TLV were considered low and other exposures were considered medium. Frequency of exposure was allocated as number of eight-hour days per year.

Several exposure metrics were constructed by combining data over the jobs over a person's entire working life: ever exposed to that substance; dose of exposure; maximum exposure level (none, low, medium, high); maximum probability of exposure (none, possible, probable); maximum frequency of days per year exposed $(0, \leq 4,>4)$; total years exposed $(0,<5, \geq 5)$. The latter two were dichotomized at approximately the 
median exposure for the control subjects. Lifetime dose of exposure was classified as substantial if the subject was probably exposed to the substance at a medium or high level, for more than five eight-hour days a year for a combined total of more than five years, and nonsubstantial if the dose was any other combination of exposures [3]. The substantial dose may have occurred during one job, or when all jobs were combined. The data were first examined by use of contingency tables and comparisons of means. Logistic regression was used to compare the risk of NHL for each exposure (for ever exposed and dose of exposure separately) adjusting for age, sex, state of residence and ethnic origin.

Logistic regression analyses were repeated for any solvents, any metals, any organic dusts, and PCBs on the following subgroups of subjects: for males only; after excluding cases that were not on the electoral roll; and restricting to B-cell NHLs only. They were also repeated for maximum exposure level, maximum probability of exposure; maximum frequency of days per year exposed; total years exposed (level of significance is $p<0.05$ ).

Approval for this study was given by the human research ethics committee at each participating institution. Written informed consent was obtained from each participant in the research.

\section{Results}

Altogether, 1230 apparently eligible cases were ascertained for the study; 210 of them were subsequently found to be ineligible because of prior immunosuppression or immune deficiency (28), poor English (73), illness (73), disability preventing interview (36), deceased (144) or could not be contacted (34). Of the remaining 842 who were approached for interview, 717 (85\%) were interviewed ( $70 \%$ of those potentially eligible). Twentythree of these were excluded after the pathology reviews because of low confidence in the diagnosis of NHL. Thus, 694 cases were left for analysis.

A total of 1687 apparently eligible controls were randomly selected for the study; 145 of them were subsequently found to be ineligible because of poor English (74), illness (59), disability preventing interview (12), deceased (5) or could not be contacted (401). Of the 1136 who were approached for interview, 694 (61\%) were interviewed ( $45 \%$ of those potentially eligible).

Cases and controls were well matched by sex, age and state and had similar proportions of ever smokers (Table 1). Cases were more likely to be of British/Irish ethnic origin possibly because of a relative deficit of people of other origins on the electoral roll [14]. 15\% of the cases were not listed on the electoral roll.
Table 1. Characteristics of non-Hodgkin lymphoma cases and controls

\begin{tabular}{lll}
\hline & $\begin{array}{l}\text { Cases n (\%) } \\
\mathrm{N}=694\end{array}$ & $\begin{array}{l}\text { Controls n (\%) } \\
\mathrm{N}=694\end{array}$ \\
\hline Male sex & $404(58.2)$ & $397(57.2)$ \\
On electoral roll & $584(84.1)$ & $694(100)$ \\
Ever smoked & $378(54.5)$ & $365(52.6)$ \\
Age group (years) & & \\
$20-29$ & $20(2.9)$ & $21(3.0)$ \\
$30-39$ & $43(6.2)$ & $46(6.6)$ \\
$40-49$ & $119(17.1)$ & $114(16.4)$ \\
$50-59$ & $204(29.4)$ & $195(28.1)$ \\
$60-69$ & $211(30.4)$ & $209(30.1)$ \\
$70-74$ & $97(14.0)$ & $109(15.7)$ \\
Ethnic origin & & \\
British/Irish & $508(73.2)$ & $545(78.5)$ \\
Asian & $23(3.3)$ & $14(2.0)$ \\
Southern European & $40(5.8)$ & $22(3.2)$ \\
West/North European & $32(4.6)$ & $24(3.5)$ \\
Mixed & $66(9.5)$ & $65(9.4)$ \\
Other & $25(3.6)$ & $24(3.5)$ \\
State & & $661(95.2)$ \\
$\quad$ New South Wales & $666(96.0)$ & $33(4.8)$ \\
Australian Capital & $28(4.0)$ & \\
Territory & & \\
\hline
\end{tabular}

Prevalence of exposure ranged from $31.1 \%$ of subjects for any solvents to $1.9 \%$ for PCBs. $18.5 \%$ of subjects were exposed to metals and $18.3 \%$ were exposed to organic dusts.

\section{Ever exposed}

The risk of NHL was increased by about $30 \%$ for subjects ever exposed to any solvents $(\mathrm{OR}=1.29,95 \%$ CI 1.01-1.64) (Table 2). The risk was similar, but was not statistically significant, for exposure to aliphatic solvents and aromatic solvents (other than benzene) but the risk was not increased for exposure to benzene alone. Risks were not increased for exposure to metal dusts. Risk was not significantly increased with probable exposure to organic dusts as a group $(\mathrm{OR}=1.21,95 \%$ CI 0.92-1.61). For individual organic dust subgroups, the risk of NHL with exposure to hardwoods and softwoods were increased but this was only statistically significant for softwoods $(\mathrm{OR}=1.64$, 95\% CI $1.05-$ 2.59). If we combined exposure to either soft or hard woods, the risk of NHL was significantly increased $(\mathrm{OR}=1.58,95 \%$ CI 1.01-2.47). Exposure to PCBs did not increase the risk of NHL.

\section{Dose of exposure}

There was a significant dose-response relationship between NHL and exposure to any solvents and to aliphatic 
Table 2. Numbers of subjects exposed to substances and odds ratio and $95 \% \mathrm{CI}$ for non-Hodgkin lymphoma adjusting for age, sex, state and ethnic origin

\begin{tabular}{|c|c|c|c|}
\hline $\begin{array}{l}\text { Exposure to } \\
\text { substance }\end{array}$ & $\begin{array}{l}\text { No. of } \\
\text { controls }\end{array}$ & $\begin{array}{l}\text { No. of } \\
\text { cases }\end{array}$ & $\begin{array}{l}\text { Odds ratio } \\
(95 \% \mathrm{CI})\end{array}$ \\
\hline \multicolumn{4}{|l|}{ Any solvents } \\
\hline No & 495 & 463 & 1.0 \\
\hline Yes & 199 & 231 & $1.29(1.01-1.64)$ \\
\hline \multicolumn{4}{|l|}{ Benzene } \\
\hline No & 631 & 626 & 1.0 \\
\hline Yes & 63 & 68 & $1.09(0.75-1.59)$ \\
\hline \multicolumn{4}{|c|}{ Other aromatics } \\
\hline No & 562 & 538 & 1.0 \\
\hline Yes & 132 & 156 & $1.28(0.97-1.68)$ \\
\hline \multicolumn{4}{|l|}{ Aliphatics } \\
\hline No & 530 & 504 & 1.0 \\
\hline Yes & 164 & 190 & $1.25(0.97-1.61)$ \\
\hline \multicolumn{4}{|l|}{ Chlorinated } \\
\hline No & 654 & 651 & 1.0 \\
\hline Yes & 40 & 43 & $1.11(0.70-1.73)$ \\
\hline \multicolumn{4}{|l|}{ Any metals } \\
\hline No & 569 & 562 & 1.0 \\
\hline Yes & 125 & 132 & $1.05(0.79-1.40)$ \\
\hline \multicolumn{4}{|l|}{ Toxic metals } \\
\hline No & 594 & 601 & 1.0 \\
\hline Yes & 100 & 93 & $0.90(0.65-1.24)$ \\
\hline \multicolumn{4}{|l|}{ Other metals } \\
\hline No & 599 & 584 & 1.0 \\
\hline Yes & 95 & 110 & $1.21(0.88-1.66)$ \\
\hline \multicolumn{4}{|c|}{ Any organic dusts } \\
\hline No & 575 & 557 & 1.0 \\
\hline Yes & 119 & 137 & $1.21(0.92-1.61)$ \\
\hline \multicolumn{4}{|l|}{ Hardwoods } \\
\hline No & 661 & 646 & 1.0 \\
\hline Yes & 33 & 48 & $1.48(0.93-2.37)$ \\
\hline \multicolumn{4}{|l|}{ Softwoods } \\
\hline No & 660 & 640 & 1.0 \\
\hline Yes & 34 & 54 & $1.64(1.05-2.59)$ \\
\hline \multicolumn{4}{|l|}{ Cotton dust } \\
\hline No & 686 & 684 & 1.0 \\
\hline Yes & 8 & 10 & $1.24(0.48-3.18)$ \\
\hline \multicolumn{4}{|l|}{ Grain dust } \\
\hline No & 633 & 635 & 1.0 \\
\hline Yes & 61 & 59 & $0.98(0.67-1.44)$ \\
\hline \multicolumn{4}{|l|}{ Other organic } \\
\hline No & 671 & 658 & 1.0 \\
\hline Yes & 23 & 36 & $1.62(0.95-2.78)$ \\
\hline \multicolumn{4}{|l|}{ PCBs } \\
\hline No & 682 & 681 & 1.0 \\
\hline Yes & 12 & 13 & $1.10(0.49-2.44)$ \\
\hline
\end{tabular}

solvents (Table 3). For aromatic solvents (other than benzene) there was also a dose response relationship which just failed to reach statistical significance. When the
Table 3. Numbers of subjects substantially and non-substantially exposed to substances and odds ratio and 95\% CI for non-Hodgkin lymphoma adjusting for age, sex, state and ethnic origin. All odds ratios are given in reference to subjects unexposed to that substance

\begin{tabular}{|c|c|c|c|c|}
\hline Substance & $\begin{array}{l}\text { No. of } \\
\text { controls } \\
\text { exposed }\end{array}$ & $\begin{array}{l}\text { No. of } \\
\text { cases } \\
\text { exposed }\end{array}$ & $\begin{array}{l}\text { Odds ratio } \\
(95 \% \mathrm{CI})\end{array}$ & $\begin{array}{l}p \text { For } \\
\text { trend }\end{array}$ \\
\hline \multicolumn{5}{|l|}{ Any solvents } \\
\hline Nonsubstantial & 161 & 183 & $1.25(0.97-1.62)$ & 0.04 \\
\hline Substantial & 38 & 48 & $1.45(0.92-2.29)$ & \\
\hline \multicolumn{5}{|l|}{ Benzene } \\
\hline Nonsubstantial & 56 & 66 & $1.19(0.81-1.74)$ & 0.98 \\
\hline Substantial & 7 & 2 & $0.31(0.06-1.50)$ & \\
\hline \multicolumn{5}{|l|}{ Other aromatics } \\
\hline Nonsubstantial & 114 & 131 & $1.24(0.92-1.65)$ & 0.06 \\
\hline Substantial & 18 & 25 & $1.55(0.83-2.91)$ & \\
\hline \multicolumn{5}{|l|}{ Aliphatics } \\
\hline Nonsubstantial & 131 & 143 & $1.16(0.89-1.53)$ & 0.04 \\
\hline Substantial & 33 & 47 & $1.59(0.99-2.56)$ & \\
\hline \multicolumn{5}{|l|}{ Chlorinated } \\
\hline Nonsubstantial & 36 & 36 & $1.03(0.64-1.66)$ & 0.51 \\
\hline Substantial & 4 & 7 & $1.81(0.52-6.23)$ & \\
\hline \multicolumn{5}{|l|}{ Any metals } \\
\hline Nonsubstantial & 92 & 89 & $0.96(0.69-1.33)$ & 0.46 \\
\hline Substantial & 33 & 43 & $1.32(0.81-2.14)$ & \\
\hline \multicolumn{5}{|l|}{ Toxic metals } \\
\hline Nonsubstantial & 82 & 65 & $0.76(0.53-1.09)$ & 0.90 \\
\hline Substantial & 18 & 28 & $1.55(0.84-2.87)$ & \\
\hline \multicolumn{5}{|l|}{ Other metals } \\
\hline Nonsubstantial & 66 & 76 & $1.21(0.84-1.74)$ & 0.28 \\
\hline Substantial & 29 & 34 & $1.21(0.71-2.04)$ & \\
\hline \multicolumn{5}{|l|}{ Any organic dust } \\
\hline Nonsubstantial & 103 & 115 & $1.18(0.88-1.59)$ & 0.15 \\
\hline Substantial & 16 & 22 & $1.44(0.74-2.80)$ & \\
\hline \multicolumn{5}{|l|}{ Hardwoods } \\
\hline Nonsubstantial & 21 & 34 & $1.67(0.95-2.94)$ & 0.17 \\
\hline Substantial & 12 & 14 & $1.21(0.55-2.67)$ & \\
\hline \multicolumn{5}{|l|}{ Softwoods } \\
\hline Nonsubstantial & 25 & 40 & $1.66(0.99-2.79)$ & 0.05 \\
\hline Substantial & 9 & 14 & $1.61(0.68-3.79)$ & \\
\hline
\end{tabular}

risk of NHL with combined exposure to any wood dust was examined the trend was not statistically significant (substantial dose $\mathrm{OR}=1.68,95 \%$ CI $0.99-2.86$; nonsubstantial dose $\mathrm{OR}=1.37,95 \%$ CI $0.63-2.95$ ). There were insufficient subjects exposed to substantial doses of grain dusts, cotton dusts, other organic dusts and PCBs to reliably assess the dose response relationship.

\section{Subgroups of subjects}

Restricting the cases to those on the electoral roll (to improve comparability with controls) did not 
Table 4. Risk of non-Hodgkin lymphoma with exposure to various chemicals for different subgroups of the study adjusting for sex, age, ethnicity and region of residence

\begin{tabular}{|c|c|c|c|c|c|}
\hline Subgroup & Ever exposed & Any solvents & Any metals & Any organic dusts & PCBs \\
\hline \multirow{2}{*}{$\begin{array}{l}\text { Electoral roll } \\
\text { controls only }\end{array}$} & No & 1.0 & 1.0 & 1.0 & 1.0 \\
\hline & Yes & $1.25(0.97-1.61)$ & $1.05(0.78-1.42)$ & $1.12(0.84-1.51)$ & $1.20(0.53-2.72)$ \\
\hline \multirow[t]{2}{*}{ Males only } & No & 1.0 & 1.0 & 1.0 & 1.0 \\
\hline & Yes & $1.40(1.05-1.85)$ & $1.03(0.76-1.40)$ & $1.32(0.96-1.83)$ & $1.09(0.47-2.52)$ \\
\hline \multirow[t]{2}{*}{ B-cell cases only } & No & 1.0 & 1.0 & 1.0 & 1.0 \\
\hline & Yes & $1.30(1.02-1.67)$ & $1.04(0.78-1.40)$ & $1.23(0.93-1.64)$ & $1.18(0.53-2.62)$ \\
\hline
\end{tabular}

substantially change the results (Table 4). The point estimates for men only were slightly higher than those for the combined group of subjects. Very few females were exposed to the substances of interest, especially at substantial levels (fewer than ten to each substance). Restricting the analysis to those cases with B-cell lymphoma did not change the estimates substantially.

\section{Different exposure metrics}

Those subjects whom the expert thought may only possibly have been exposed to the substances tended to have lower risks of NHL than those with probable exposure (Table 5). This was especially so for PCBs in which those with probable exposure had about four times the risk of NHL although confidence intervals were very wide $(\mathrm{OR}=4.54,95 \%$ CI $0.97-21.2)$. For exposure to any solvents, the more frequent that exposure was, and the more years the subject were exposed, the greater the risk of NHL. There were no other significant dose-response relationships for the different metrics of exposure.

\section{Discussion}

The literature on occupational causes of non-Hodgkin lymphoma is extensive and inconsistent. Many studies have combined NHL with Hodgkin's lymphoma, multiple myeloma and leukemias, although it is probable that these diseases have different causes. Other studies have had small numbers of cases and others used job titles, or self-assessed occupational exposures. Our large casecontrol study of histologically-confirmed non-Hodgkin

Table 5. Different metrics of exposure to various chemicals and risk of non-Hodgkin lymphoma adjusting for sex, age, ethnicity and region of residence

\begin{tabular}{|c|c|c|c|c|}
\hline Exposure & Any solvents & Any metals & Any organic dusts & PCBs \\
\hline \multicolumn{5}{|l|}{ Probability } \\
\hline No & 1.0 & 1.0 & 1.0 & 1.0 \\
\hline Possible & $0.98(0.52-1.85)$ & $0.75(0.31-1.82)$ & $1.40(0.61-3.23)$ & $0.40(0.12-1.31)$ \\
\hline Probable & $1.33(1.03-1.71)$ & $1.08(0.80-1.46)$ & $1.20(0.89-1.60)$ & $4.54(0.97-21.2)$ \\
\hline \multicolumn{5}{|l|}{ Level } \\
\hline None & 1.0 & 1.0 & 1.0 & 1.0 \\
\hline Low & $1.05(0.86-1.55)$ & $0.90(0.58-1.39)$ & $1.32(0.86-2.02)$ & $1.91(0.75-4.85)$ \\
\hline Medium & $1.54(1.09-2.19)$ & $1.13(0.77-1.65)$ & $1.04(0.73-1.48)$ & $0.78(0.17-3.50)$ \\
\hline High & $0.92(0.46-1.83)$ & $1.22(0.62-2.42)$ & $1.93(0.64-5.82)$ & - \\
\hline$p$ For trend & 0.07 & 0.5 & 0.3 & 0.9 \\
\hline \multicolumn{5}{|l|}{ Frequency } \\
\hline Never & 1.0 & 1.0 & 1.0 & 1.0 \\
\hline$\leq 4$ days per year & $1.25(0.91-1.72)$ & $1.0(0.66-1.50)$ & $1.67(0.99-2.80)$ & $1.44(0.49-4.22)$ \\
\hline$>4$ days per year & $1.44(1.05-1.97)$ & $1.10(0.74-1.62)$ & $1.13(0.70-1.82)$ & $1.15(0.35-3.81)$ \\
\hline$p$ For trend & 0.02 & 0.7 & 0.2 & 0.6 \\
\hline \multicolumn{5}{|l|}{ Years } \\
\hline Never & 1.0 & 1.0 & 1.0 & 1.0 \\
\hline$<5$ years & $1.23(0.84-1.80)$ & $0.95(0.59-1.53)$ & $1.35(0.87-2.11)$ & $1.04(0.26-4.19)$ \\
\hline $5+$ years & $1.31(1.00-1.72)$ & $1.09(0.78-1.52)$ & $1.17(0.84-1.63)$ & $1.13(0.43-2.97)$ \\
\hline$p$ For trend & 0.04 & 0.7 & 0.2 & 0.8 \\
\hline
\end{tabular}


lymphoma used the best available assessment of occupational substance exposure. We found increases in risk of NHL with exposure to solvents and possibly to wood dust and no evidence of association between NHL and exposure to metal dust, other organic dusts, or PCBs.

Our study suggests that solvents increase the risk of NHL by about $30 \%$. Many early studies examining this question used questionnaires in which the subject was asked to assess their own exposure to solvents. While this is a simple and cheap method of assessing solvent exposure, subjects tend to underestimate their exposure compared to experts reviewing job histories [15, 16]. More recent studies have used similar expert assessment methods to those we used, considered to be the best available [12]. In the US, Blair found no association between NHL and benzene $(\mathrm{OR}=1.1,95 \%$ CI $0.9-1.4)$ or other solvent exposure $(\mathrm{OR}=1.1,95 \%$ CI $0.9-1.4)$ [2]. The Montreal Case-Control study also found no association with all solvents combined (substantial exposure $\mathrm{OR}=0.9,95 \%$ CI 0.6-1.3) [3]. A Brazilian study found an association $(\mathrm{OR}=1.67,95 \%$ CI $0.97-$ 2.87 ) but was limited by the small size of the study ( $\mathrm{n}=109$ cases) [17]. Examination of time windows in this last study suggested the effect was greatest if the exposure had occurred between 15 and 25 years earlier. A Swedish study found exposure to solvents for more than five years was associated with an increased risk of NHL $(O R=1.59,95 \%$ CI 1.11-2.28) [18]. Several recent studies have examined the risks of NHL by occupational group, and although one of these found an increased risk of NHL in occupations known to have exposure to solvents [19], others did not [20, 21]. Specific substance exposure was not assessed in these studies so misclassification would have been likely.

When we examined different types of solvents we found that the effect was limited to solvents other than benzene. The question of whether benzene exposure causes NHL has been controversial. Recent reviews have concluded that, while benzene is probably a risk factor for leukaemia, it is less likely to be a risk factor for NHL [4, 22]. Most of the work on benzene has been done in cohorts of petroleum workers. A recent nested case-control study with very intensive assessment of benzene exposure found no association with NHL $(\mathrm{OR}=1.1,95 \%$ CI $0.3-4.5)$ for exposure of more than 16 ppm-years [23]. However, a cohort study in China found that workers exposed to benzene had three times the risk of NHL compared with unexposed subjects $(\mathrm{OR}=3.0,95 \%$ CI 0.9-10.5) [24].

We found that exposure to aromatic (other than benzene) or aliphatic solvents increased the risk of NHL by about $30 \%$, although the effect was not always statistically significant. Few subjects were exposed to substantial levels of these solvents, but those who were had about a $50 \%$ increase in risk. Aromatic solvents such as toluene and xylene have been inconsistently linked to NHL [4]. Two large cohort studies of manufacturing workers exposed primarily to toluene showed no increase in risk of NHL when compared to the general population $[25,26]$. A recent Swedish study found that NHL risk was increased with exposure to aliphatic or alicyclic hydrocarbons $(\mathrm{OR}=1.75,95 \% \mathrm{CI}$ 1.03-2.99) and aromatic hydrocarbons $(\mathrm{OR}=1.45,95 \%$ CI 1.13-1.86) [18].

We found the risk of NHL increased by nearly $80 \%$ with substantial exposure to chlorinated solvents, although numbers of exposed subjects were low. A meta-analysis of studies of trichloroethylene found a risk of 1.5 (95\% CI 0.9-2.3) when the results of four methodologically strong cohort studies were combined [27].

The PCBs are a group of organochlorine compounds which have been used in electrical equipment such as transformers and capacitors because of their insulating and flame resisting qualities. No PCBs were manufactured in Australia but they were used in the electricity and manufacturing industries. Occupational exposure to PCBs was very rare in our study with only 25 subjects possibly or probably exposed. In 1997, a nested casecontrol study in the United States found a strong doseresponse relationship between pre-diagnostic serum PCB concentrations and NHL [7]. A case-control study of NHL found similar associations with adipose tissue concentrations of PCBs [28]. In both these studies, the subjects had environmental rather than occupational exposure to PCBs. Australian environmental PCB contamination is thought to be similar to that in other urbanized countries [29-31]. Studies from cohorts of workers exposed to PCBs in capacitor manufacturing or power generation have often had small numbers of workers and few cases or deaths from NHL. The largest study was a cohort of nearly 140,000 electrical utility workers with 176 deaths from NHL [32]. The standardized mortality rate (SMR) in this study was 104 (95\% CI 89-120) but exposure levels were probably relatively low. Other more highly exposed cohorts have had fewer than 20 deaths from NHL and SMRs in the range of 68 to 254, none of which were statistically significant [33-38].

Several registry-based studies have suggested that work in metal related industries and jobs such as machinists and welders are associated with increased risk of NHL [8, 39]. We found no association with toxic metals, other metals or all metals combined. Casecontrol studies using self-assessed occupational exposures have examined certain toxic metals including chromium, which was found to be associated with 
NHL in African-Americans $(\mathrm{OR}=3.9,95 \%$ CI $1.2-$ 12.9) but not European-Americans (OR $=1.0,95 \% \mathrm{CI}$ 0.7-1.4) [40]. Another American study found self assessed exposure to heavy metals was not associated with NHL $(\mathrm{OR}=1.2,95 \%$ CI $0.7-2.3)$ [41]. The Montreal study found associations with bronze dust $(\mathrm{OR}=2.8,95 \%$ CI 0.8-9.1) and copper dust $(\mathrm{OR}=5.5$, $95 \%$ CI 1.9-16.0) which are both in the "other metals" grouping in our study [3]. Blair found no association with metals exposure as assessed using a job exposure matrix [2]. Some metal working jobs are also associated with solvent use, which may be the causative factor.

The hypothesis that NHL may be a complication of the autoimmune process occurring after prolonged antigenic stimulation was first suggested in the 1970s and the occupational corollaries of this theory were reviewed by Pearce in 1992 [5]. We tested whether exposure to organic dusts, including wood, cotton, and grain dust, was associated with NHL. The Montreal Case-Control Study found NHL was associated with cotton dust, but because of the small numbers of subjects exposed to cotton dust in our study, we could not test this hypothesis with any precision [3]. We had a considerable number of grain dust exposed subjects in this study, but most of these were exposed at a low level and we found no evidence that grain dust exposure was associated with NHL. A large cohort of flour industry workers found increased risk of NHL was restricted to workers employed in flour mills and the authors felt this may have been due to use of pesticides [42].

Exposure to wood dust, another organic dust examined in our study, was associated with increased effect estimates for NHL. Sawmill and forestry workers have been found to have increased risks of NHL $[43,44]$ and this led Pearce and Bethwaite [5] to suggest wood dust as an exposure that may cause NHL. However, studies that asked subjects to self-report their exposure to wood dust have not produced consistent results. One found an association among women but not men [45]; another found a higher OR amongst African-Americans than among European-Americans [40]; while a third found no association at all [46]. The Montreal Case-Control Study, which used exposure assessment methods similar to ours, did not find an association between wood dust and NHL and nor did a large study in which a job exposure matrix was used [2, 3]. Many forestry workers are exposed to pesticides and wood preservatives as well as wood.

While occupational exposures have been suggested as being risk factors for NHL, many previous studies have used inaccurate methods of exposure assessment, or have used mortality rather than incidence as their outcome. This study used state-of-the-art exposure assessments to assess occupational exposure to a number of specific substances. The expert assessment method is known to be valid when compared to measured exposures [47] and sensitivity is higher than for self assessed exposure [16]. The reliability of assessments is relatively high, with assessors agreeing on over 95\% of assessments [16]. Kappa statistics for agreement of experienced experts are about $60 \%$ [48] or $50 \%$ for assessors new to the method [49] and weighted kappas are about $80 \%$ [50]. Recall bias on occupational histories has been shown to be low [51].

Other advantages of our study were that the number of cases and controls was quite large, the study was population-based rather than hospital-based, we used incident cases not deaths, and participation, especially for cases, was reasonable. In addition, findings for solvents were robust and internally consistent. The limitations of this study include the possibility of selection bias, particularly with the use of the electoral roll as the source for controls. Although about $15 \%$ of the cases were not on the electoral roll, excluding these cases from the analysis did not substantially change the pattern of results. There was a deficit of controls from non-European backgrounds and, although we adjusted for this in the analyses, there may be residual confounding if there is an association between ethnic background and exposure to the substances.

In conclusion, our results are broadly consistent with other literature showing that occupational exposures to solvents (other than benzene) and possibly to wood dust are associated with NHL.

\section{Acknowledgments}

The study was funded by the National Health and Medical Research Council of Australia, The Cancer Council NSW and The University of Sydney Medical Foundation. Lin Fritschi is supported by a NHMRC Career Development Award. Claire Vajdic has a Postdoctoral Research Fellowship of the National Health and Medical Research Council. Ann Maree Hughes was a University of Sydney Faculty of Medicine Postgraduate Scholarship recipient. Bruce Armstrong's research is supported by a University of Sydney Medical Foundation program grant. The National Centre in HIV Epidemiology and Clinical Research is funded by the Australian Government Department of Health and Aging.

\section{References}

1. Australian Institute of Health and Welfare (AIHW) and Australasian Association of Cancer Registries. (2003). Cancer in Australia 
2000. AIHW Cat no. CAN 18. Canberra: AIHW Cancer Series no 23.

2. Blair A, Linos A, Stewart P, et al. (1993) Evaluation of risks for non-hodgkin's lymphoma by occupation and industry exposures from a case-control study. Am J Ind Med 23: 301-312.

3. Fritschi L, Siemiatycki J (1996) Lymphoma, myeloma and occupation: results of a case-control study. Int J Cancer 67: 498-503.

4. Lynge E, Anttila A, Hemminki K (1997) Organic solvents and cancer. Cancer Causes Control 8: 406-419.

5. Pearce N, Bethwaite P (1992) Increasing incidence of nonhodgkin's lymphoma: occupational and environmental factors. Cancer Res 52: 5496s-5500s.

6. Rego MA (1998) Non-Hodgkin's lymphoma risk derived from exposure to organic solvents: a review of epidemiologic studies. Cad Saude Publica 3: 41-66.

7. Rothman N, Cantor K, Blair A, et al. (1997) A nested case-control study of non-Hodgkin lymphoma and serum organochlorine residues. Lancet 350: 240-244.

8. Skov T, Lynge E (1991) Non-Hodgkin's lymphoma and occupation in Denmark. Scand J Soc Med 19: 162-169.

9. Siemiatycki J, Day NE, Fabry J, Cooper JA (1981) Discovering carcinogens in the occupational environment: a novel epidemiologic approach. J Natl Cancer Inst 66: 217-225.

10. Hughes AM, Armstrong BK, Vajdic CM, et al. (2004) Pigmentary characteristics, sun sensitivity and non-Hodgkin lymphoma. Int $J$ Cancer 110: 429-434.

11. Jaffe ES, Harris NL, Stein H, Vardiman JW (eds). (2001) Pathology and Genetics of Tumours of Hematopoeitic and Lymphoid Tissues. World Health Organization Classification of Tumors, Lyon IARC.

12. Stewart WF, Stewart PA (1994) Occupational case-control studies: I. Collecting information on work histories and work-related exposures. Am J Ind Med 26: 297-312.

13. American College of Government Industrial Hygienists (2001) Documentation of the Threshold Limit Values and Biological Exposure Indices, 7th Edn. OH, USA: ACGIH Cincinnati.

14. Vajdic CM, Kricker A, Giblin M, et al. (2001) Eye color and cutaneous nevi predict risk of ocular melanoma in Australia. Int $J$ Cancer 92: 906-912.

15. Fritschi L, Siemiatycki J, Richardson L (1996) Self-assessed versus expert-assessed occupational exposures. Am J Epidemiol 144: 521-527.

16. Benke G, Sim M, Fritschi L, Aldred G, Forbes A, Kauppinen T (2001) Comparison of occupational exposure using three different methods: hygiene panel, job exposure matrix (JEM), and self reports. Appl Occup Environ Hyg 16: 84-91.

17. Rego MA, Sousa CS, Kato M, de Carvalho AB, Loomis D, Carvalho FM (2002) Non-Hodgkin's lymphomas and organic solvents. J Occup Environ Med 44: 874-881.

18. Dryver E, Brandt L, Kauppinen T, Olsson H (2004) Occupational exposures and non-Hodgkin's lymphoma in Southern Sweden. Int J Occup Environ Health 10: 13-21.

19. Band PR, Le ND, Fang R, Gallagher R (2004) Identification of occupational cancer risks in British Columbia: a population-based case-control study of 769 cases of non-Hodgkin's lymphoma analyzed by histopathology subtypes. J Occup Environ Med 46: 479-489.

20. Cano M, Pollan M (2001) Non-Hodgkin's lymphomas and ocupation in Sweden. Int Arch Occup Environ Health 74: 443-449.

21. Costantini AS, Miligi L, Kriebel D, et al. (2001) A multicenter case-control study in Italy on hematolymphopoietic neoplasms and occupation. Epidemiology 12: 78-87.

22. Savitz D, Andrews K (1997) Review of epidemiologic evidence on benzene and lymphatic and hematopoietic cancers. Am J Ind Med 31: $287-295$.
23. Glass DC, Gray CN, Jolley DJ, et al. (2003) Leukemia risk associated with low-level benzene exposure. Epidemiology 14: 569577.

24. Hayes RB, Yin SN, Dosemeci M, Li GL, Wacholder S, Travis LB, et al. (1997) Benzene and the dose-related incidence of hematologic neoplasms in China. Chinese Academy of Preventive Medicine National Cancer Institute Benzene Study Group. J Natl Cancer Inst 89: 1065-1071.

25. Svensson BG, Nise G, Englander V, Attewell R, Skerfving S, Moller T (1990) Deaths and tumours among rotogravure printers exposed to toluene. Br J Ind Med 47: 372-379.

26. Walker JT, Bloom TF, Stern FB, Okun AH, Fingerhut MA, Halperin WE (1993) Mortality of workers employed in shoe manufacturing. Scand J Work Environ Health 19: 89-95.

27. Wartenberg D, Reyner D, Scott CS (2000) Trichloroethylene and cancer: epidemiologic evidence. Environ Health Perspect 108: 161176 .

28. Hardell L, Liljegren G, Lindstrom G, van Bavel B, Fredrikson M, Hagberg H (1997) Polychlorinated biphenyls, chlordanes, and the etiology of non-Hodgkin's lymphoma. Epidemiology 8: 689.

29. Kannan K, Tanabe S, Giesy JP, Tatsukawa R (1997) Organochlorine pesticides and polychlorinated biphenyls in foodstuffs from Asian and oceanic countries. Rev Environ Contam Toxicol 152: $1-55$.

30. Muller JF, Hawker DW, McLachlan MS, Connell DW (2001) PAHs, PCDD $/ F s, P C B s$ and $\mathrm{HCB}$ in leaves from Brisbane, Australia. Chemosphere 43: 507-515.

31. Focant JF, Pirard C, De Pauw E (2004) Levels of PCDDs, PCDFs and PCBs in Belgian and international fast food samples. Chemosphere 54: 137-142.

32. Loomis D, Browning SR, Schenck AP, Gregory E, Savitz DA (1997) Cancer mortality among electric utility workers exposed to polychlorinated biphenyls. Occup Environ Med 54: 720-728.

33. Bertazzi PA, Riboldi L, Pesatori A, Radice L, Zocchetti C (1987) Cancer mortality of capacitor manufacturing workers. Am J Ind Med 11: 165-176.

34. Brown DP (1987) Mortality of workers exposed to polychlorinated biphenyls - an update. Arch Environ Health 42: 333-339.

35. Kimbrough RD, Doemland ML, Mandel JS (2003) A mortality update of male and female capacitor workers exposed to polychlorinated biphenyls. J Occup Environ Med 45: 271-282.

36. Sinks T, Steele G, Smith AB, Watkins K, Shults RA (1992) Mortality among workers exposed to polychlorinated biphenyls. Am J Epidemiol 136: 389-398.

37. Tynes T, Reitan JB, Andersen A (1994) Incidence of cancer among workers in Norwegian hydroelectric power companies. Scand $J$ Work Environ Health 20: 339-344.

38. Yassi A, Tate R, Fish D (1994) Cancer mortality in workers employed at a transformer manufacturing plant. Am J Ind Med 25: 425-437.

39. Zheng T, Blair A, Zhang Y, Weisenburger DD, Zahm SH (2002) Occupation and risk of non-Hodgkin's lymphoma and chronic lymphocytic leukemia. J Occup Environ Med 44: 469474 .

40. Briggs NC, Levine RS, Hall HI, Cosby O, Brann EA, Hennekens CH (2003) Occupational risk factors for selected cancers among African American and White men in the United States. Am J Public Health 93: 1748-1752.

41. Scherr P, Hutchison G, Neiman R (1992) Non-Hodgkin's lymphoma and occupational exposure. Cancer Res 52: 5503s$5509 \mathrm{~s}$.

42. Alavanja MC, Blair A, Masters MN (1990) Cancer mortality in the U.S. flour industry. J Natl Cancer Inst 82: 840-848. 
43. Persson B, Fredriksson M, Olsen K, Boeryd B, Axelson O (1993) Some occupational exposures as risk factors for malignant lymphomas. Cancer 72: 1773-1778.

44. Reif J, Pearce N, Kawachi I, Fraser J (1989) Soft-tissue sarcoma non-Hodgkin's lymphoma and other cancers in New Zealand forestry workers. Int $J$ Cancer 43: 49-54.

45. Mao Y, Hu J, Ugnat AM, White K (2000) Non-Hodgkin's lymphoma and occupational exposure to chemicals in Canada. Canadian Cancer Registries Epidemiology Research Group. Ann Oncol 11: 69-73.

46. Tatham L, Tolbert P, Kjeldsberg C (1997) Occupational risk factors for subgroups of non-Hodgkin's lymphoma. Epidemiology 8: 551558.

47. Fritschi L, Nadon L, Benke G, Lakhani R, et al. (2003) Validation of expert assessment of occupational exposures. Am J Ind Med $\mathbf{4 3}$ $519-522$.
48. Goldberg MS, Siemiatycki J, Gerin M (1986) Inter-rater agreement in assessing occupational exposure in a case-control study. $\mathrm{Br} \mathrm{J}$ Ind Med 43: 667-676.

49. Benke G, Sim M, Forbes A, Salzberg M (1997) Retrospective assessment of occupational exposure to chemicals in communitybased studies: validity and repeatability of industrial hygiene panel ratings. Int J Epidemiol 26: 635-642.

50. Siemiatycki J, Fritschi L, Nadon L, Gerin M (1997) Reliability of an expert rating procedure for retrospective assessment of occupational exposures in community-based case-control studies. Am J Ind Med 31: 280-286.

51. Baumgarten M, Siemiatycki J, Gibbs GW (1983) Validity of work histories obtained by interview for epidemiologic purposes. Am J Epidemiol 118: 583-591. 